\title{
Mastering Multimedia: Teaching Languages Through Technology
}

\author{
Selected papers from EUROCALL 2007
}

\author{
JOHN GILLESPIE
}

University of Ulster, Coleraine, Northern Ireland

\begin{abstract}
Where have we got to?
Uschi Felix, in her plenary at EUROCALL 2007, characterised the organisation as being in its adolescence since it was formally founded fourteen years ago in Hull. But adolescents are often troubled, self-questioning and moody. That was not the atmosphere at EUROCALL. While there was not exactly a coming-of-age feeling, it was clear, in this age of digital multimedia, that the work we are doing is not only valuable and valued but also central to the educational process. This has never been the case before. Plenaries, Research Presentations and Show and Tell sessions all reflected this conviction.
\end{abstract}

\section{Our digital age}

Many, in recognising that we are living in a digital age, quoted Prensky's categories of digital immigrants and digital natives, albeit indirectly. Digital technology has flowed into the mainstream of teaching and learning in Higher Education, although not in an unproblematic way. So much of our lives outside education has been influenced by Web technologies in particular. Everything has changed. Broadband, mobile technologies, podcasts, and social software are part and parcel of everyday life. Students coming to university are looking for a similar level of digital resource, and they are increasingly getting it. Interconnectivity is expected and the integration of technology into teaching, already present in many primary and secondary institutions (in the UK at least), taken for granted.

These are exciting times; however, the generation shift from immigrants to natives has not yet taken place within the CALL community. The integration of digital and multimedia technologies is patchy. That is our key challenge. How can we, in a multimedia age, integrate their benefits into teaching and learning?

\section{Connected and collaborative}

The major shift has been accessibility to people and information through the Web 
(whether it be 2.0 or 9.0). Bernd Rüschoff's plenary outlined its key advantages for the development of collaborative learning. Social software, wikis, blogs, podcasts and videocasts are second nature to our digital native students and can revolutionise learning and peer learning. The wisdom of the crowd should not be spurned. Collaboration and participation can not only help to develop language skills, but also life skills. The emphasis on activity, agency and output in 'languaging' is vastly more effective in a computer-based environment that in the traditional classroom.

The connectivity of the conference itself reflected this reality. Almost everything was administered through the Web: papers were proposed and reviewed, participants registered, podcasts of the presentations made available post-conference (with frequent hits on the web-site even yet), and, through the highly innovative and successful virtual strand - well done all concerned - as many people were able to follow the conference virtually as attended it in person (ca. 240), with the plenaries and the panel session streamed live across the world, and still available on the web-site. We even had a question from a virtual participant in the panel session!

\section{Learner centred}

Meeting the challenge means changing and adapting to this situation with the same degree of sophistication as learners do. Gráinne Conole's plenary talk showed how students incorporate technology into their everyday lives, both for study and for leisure, in a sophisticated manner. Significantly they view technological devices merely as tools among the great variety available to them. There are still problems here. The digital natives may be at home in their digital, multimedia world, but their use of technology for entertainment does not mean that they are always willing and able to use it for study. In fact they need to learn how to learn, digitally and in every other way. They may integrate personal tools in an organised way into their activities using a diverse range of technologies to complete specific tasks, but the questions of depth of understanding and effectiveness of performance are still present.

\section{Pedagogically alert}

We were challenged, as language teachers, to integrate technology appropriately into our practice. Once again the message was clear - sound pedagogy should be at the centre of our deliberations, and effective learning methods for students should preoccupy us, not the latest technological phenomenon. So initial teacher training in the use of technology, as well as the retraining of the 'old lags', was seen as central. Teaching without the use of technology is fine. And so is exploiting digital technology in the flexible classroom - a workshop, teaching space, computer laboratory, communication centre or learning observatory. If, in language learning, we stress languaging and emphasise language outputs, multimedia technologies, especially Web 2.0 , are ideal.

\section{Rigorous in research}

All this requires reflective practice, research and innovation. Uschi Felix, in her plenary, 
ranged magisterially over two decades of CALL research into its effectiveness and its limitations. She underlined the need to meet the methodological challenges of research of different areas of teaching by rigorous, carefully designed and targeted projects (on, for instance, meta-cognitive skills) which emphasise both the quantitative and qualitative study of learning processes and outcomes.

\section{Technologically enhanced}

Confronted with what appears to be an ever-accelerating pace of change, with occasional quantum leaps in technological capacity, how can we face the future? The message was clear - by knowing what is available, by objectively assessing its strengths and weaknesses, by proper research, and by being prepared to say no to developments which we do not see as helpful for our situations, whether personal or institutional. We should choose the technology that enhances our capacity to teach and enables our learners to learn. That is the only sensible and practical path.

The conference was a wonderful experience for us at Ulster, particularly in having the privilege of hosting Uschi's last plenary before her retirement. It was also great to welcome Graham Chesters, an old friend, before his retirement and to greet friends and colleagues from EUROCALL to a Northern Ireland at peace. My thanks to all involved in the organisation of the conference for their tireless work and to all who attended for their enthusiastic participation in everything that took place.

This issue contains four of the papers delivered at the conference, so you will be able to reflect in detail on these questions. Further papers will appear in later issues of ReCALL. 